\title{
Lanthanides and actinides in ionic liquids
}

\author{
Koen Binnemans \\ Katholieke Universiteit Leuven, Department of Chemistry, \\ Celestijnenlaan 200F, B-3001 Leuven (BELGIUM) \\ E-mail: Koen.Binnemans@chem.kuleuven.be
}

This lecture gives an overview of the research possibilities offered by combining felements (lanthanides and actinides) with ionic liquids [1] Many ionic liquids are solvents with weakly coordinating anions. Solvation of lanthanide and actinide ions in these solvents is different from what is observed in conventional organic solvents and water. The poorly solvating behavior can also lead to the formation of coordination compounds with low coordination numbers. The solvation of f-elements can be simulated by molecular dynamics simulations with explicit representation of the solvent, or can be directly probed by spectroscopic methods. Ionic liquids turn out to be a promising solvent for near-infrared emitting lanthanide complexes [2]. It is often mentioned that one of the main advantages of ionic liquids is their resistance to strongly oxidizing or reducing agents, i.e. ionic liquids have a large electrochemical window. However, not all ionic liquids are suitable for study of the electrochemical properties and electrodeposition of f-elements. The metals of the lanthanides and actinides are very electropositive elements, and they will reduce imidazolium cations. More resistant against reduction are quaternary ammonium and phosphonium cations. Ionic liquids offer a large potential in the field of processing of spent nuclear fuel elements. The advantage is that the processing can be carried out at much lower temperature in ionic liquids than in inorganic molten salts. This reduces not only the energy cost, but also increases the safety. The fact that several ionic liquids strongly absorb neutrons (especially boron- and chlorine-containing ionic liquids), reduces the risk of criticality accidents. The study of metal-catalyzed organic reactions in ionic liquid media is a very popular research theme. It is therefore not surprising that lanthanide-mediated organic reactions are being performed in ionic liquids as well. The possibility to recycle the lanthanide catalyst that is immobilized in the ionic liquid and the possibility of easy product separation have stimulated researchers to work in this field. However, in only a few cases the use of (expensive) ionic liquids can be justified by the higher reactivity or selectivity. Cerium-mediated oxidation reactions in ionic liquids will be discussed [3]. The combination of lanthanides and ionic liquids can lead to new types of advanced materials (luminescent or magnetic liquid crystals, ionogels, nanoparticles, ...) [4,5]. Anionic lanthanide complexes can be the constituent of metal-containing ionic liquids [6].

[1] K. Binnemans, Chem. Rev. 107 (2007) in press.

[2] S. Arenz, A. Babai, K. Binnemans, K. Driesen, R. Giernoth, A.V. Mudring, P.

Nockemann, Chem. Phys. Lett. 402 (2005) 75-79.

[3] H. Mehdi, A. Bodor, D. Lantos, I.T. Horváth, D.E. De Vos, K. Binnemans,

J. Org. Chem. 72 (2007) 517-524.

[4] K. Binnemans, Chem. Rev. 105 (2005) 4148-4204.

[5] K. Lunstroot, K. Driesen, P. Nockemann, C. Görller-Walrand, K. Binnemans, S. Bellayer, J. Le Bideau, A. Vioux, Chem. Mater. 18 (2006) 5711-5715.

[6] P. Nockemann, B. Thijs, N. Postelmans, K. Van Hecke, L. Van Meervelt, K. Binnemans, J. Am. Chem. Soc. 128 (2006) 13658-13659. 